\title{
Desempenho de estratégias de aeração de milho armazenado: Fungos e condutividade elétrica
}

\author{
Vânia R. G. Nascimento ${ }^{1}$, Marlene R. de Queiroz ${ }^{1}$, \\ Vanessa C. Marchi ${ }^{1} \&$ Rosa H. Aguiar ${ }^{1}$
}

\begin{abstract}
RESU M 0
O bjetivou-se, com o presente trabalho, avaliar e comparar o desempenho de três estratégias de aeração de milho armazenado quanto à ocorrência de fungos e à condutividade elétrica dos grãos. As estratégias avaliadas foram: aeração contínua; aeração noturna e aeração em condições de umidade de equilíbrio entre os grãos e o ar ambiente. Realizaram-se dois ensaios de aeração com grãos de milho secos ( $11 \%$ b.u.) e úmidos ( $17 \%$ b.u.). A mostras de grãos foram retiradas durante os ensaios para contagem de fungos e medida da condutividade elétrica dos grãos. Grãos armazenados úmidos apresentaram maior ocorrência de fungos do que grãos armazenados secos. O bservou-se que o Fusarium spp. apresentou contagens mais elevadas, o Penicillium spp. manifestou desenvolvimento e o Aspergillus spp. ocorreu com menor frequência. As estratégias de aeração empregadas não interferiram na condutividade elétrica dos grãos de milho armazenados, visto que não houve diferença significativa dos valores de condutividade elétrica entre os grãos submetidos a aeração e os grãos armazenados sem aeração.
\end{abstract}

Palavras-chave: armazenamento, Aspergillus spp., Penicillium spp., Fusarium spp.

\section{Performance of aeration strategies for stored corn: Molds and electrical conductivity}

\begin{abstract}
The aim of this study was to evaluate and to compare the performance of three aeration strategies for stored corn as for occurrence of molds and electrical conductivity of grain: continuous aeration; night aeration and aeration under equilibrium moisture content conditions between the grains and the ambient air. Two tests of aeration with dry corn grain ( $11 \%$ w.b.) and wet corn ( $17 \%$ w.b.) were done. Grain samples were taken during testing for counting of molds and measuring of electrical conductivity of grains. Wet corn stored had increased incidence of molds more than dry corn stored. It was observed that the Fusarium spp. showed higher scores, Penicillium spp. showed development and Aspergillus spp. occurred with lesser frequency. Aeration strategies employed did not affect the electrical conductivity of corn stored because there was no significant difference in electrical conductivity values between the aerated grain and non-aerated grains.
\end{abstract}

Key words: storage, Aspergillus spp., Penicillium spp., Fusarium spp. 


\section{INTRODUÇÃO}

Danos provocados por fungos em grãos vão além dos físicos ou estéticos, podendo também causar o desenvolvimento de toxinas. Algumas espécies de fungos denominados toxigênicos, podem produzir micotoxinas, substâncias químicas provenientes do metabolismo secundário de diversos fungos, capazes de provocar doenças graves, como tumores cancerígenos. No entanto, somente a presença do fungo toxigênico não implica na produção de micotoxina, visto que dependerá da capacidade de biossíntese do fungo e das condições climáticas existentes.

Os fungos do gênero Fusarium spp., por exemplo, se desenvolvem favoravelmente em temperatura na faixa de 20 a $25^{\circ} \mathrm{C}$; contudo, suas toxinas são produzidas sob condições de baixas temperaturas, como a zearalenona, que é produzida sob temperatura ótima de 10 a $12^{\circ} \mathrm{C}$. Deste modo, o Fusarium spp. produz micotoxinas sob o efeito de choque térmico. Condições climáticas de alternância de altas temperaturas no dia e baixas durante a noite, favorecem a formação dessas toxinas (Bhatnagar et al., 1992).

Dentre os fungos toxigênicos se destacam os pertencentes aos gêneros Fusarium spp., Aspergillus spp. e Penicillium spp. (Silva et al., 2007), sendo esses os principais deterioradores de milho armazenado e patógenos de sementes (Machado, 1988; Ribeiro et al., 2003). Kawashima \& Soares (2006) apontam a presença de fungos toxigênicos no milho com predominância de Fusarium, seguido de Penicillium e Aspergillus.

Machado (1988) não apenas reporta que na fase de armazenamento o risco de contaminação de sementes com fungos patogênicos é dependente do controle de fatores ambientais como ressalta que colheitas sob condições úmidas ou executadas com equipamentos desregulados podem propiciar, desde o campo, a associação de fungos, como Aspergillus spp. e Penicillium spp. Esses fungos podem depreciar a qualidade das sementes quanto ao poder germinativo, pela colonização do embrião; causar descoloração e apodrecimento, com reflexos tanto na viabilidade como no valor comercial e nutritivo das sementes; aumentar a taxa de ácidos graxos, provocando rancificação de óleos; gerar aquecimento da massa de sementes devido ao aumento da taxa respiratória e, com isto, uma deterioração mais rápida, além de produzir micotoxinas, substâncias que podem ser letais ao homem e aos animais.

Pinto et al. (2007) avaliaram o desempenho de 36 cultivares de milho em relação à produção de grãos ardidos (Fusarium subglutinans) e mofados (Penicillium oxalicum) na fase de pré-colheita, assim como a biossíntese de fumonisina $\mathrm{B}_{1}$ pelo fungo toxigênico Fusarium subglutinans e notaram que a produção de grãos ardidos e mofados varia em função das cultivares de milho e que a produção de fumonisina está relacionada com a interação entre a cultivar e o fungo Fusarium subglutinans.

Amaral et al. (2006) pesquisaram a ocorrência de aflatoxinas produzidas por fungos do gênero Aspergillus, em produtos alimentícios à base de milho comercializados nas cidades de Maringá e Marialva, Paraná, e observaram baixa ocorrência de aflatoxinas; entretanto, a ingestão diária provável média de
Aflatoxina B1 foi acima da ingestão diária tolerável, indicando um risco de hepatocarcinogenicidade na população brasileira da Região Sul do Brasil, em razão do consumo desses produtos.

Tanaka et al. (2001) estudaram a sobrevivência de fungos associados às sementes de milho durante 12 meses de armazenamento em câmara fria $\left(14^{\circ} \mathrm{C} ; 40 \%\right.$ UR) e em ambiente não controlado e concluíram que a sobrevivência dos fungos de campo decresceu durante o armazenamento em condições ambientes, quando comparado com o armazenamento em câmara fria.

A utilização da condutividade elétrica de grãos e sementes vem ganhando espaço em determinação de qualidade desses produtos. Este teste avalia indiretamente o grau de integridade das membranas celulares considerando-se que, quando imersas em água, sementes de baixo vigor liberam maior quantidade de eletrólitos (Torres et al., 2009).

Rosa et al. (2000) e Costa \& Carvalho (2006) utilizaram o teste de condutividade elétrica para classificar lotes de milho com diferentes danos causados pela secagem e consideraram o teste eficiente, rápido e prático.

Lin (1988) verificou correlação entre o aumento da lixiviação eletrolítica com a perda do vigor e da germinação em sementes de milho submetidas a armazenamento sob condições de $25^{\circ} \mathrm{C}$ e $79 \%$ de umidade relativa, durante o tempo de 92 dias.

Nesse contexto, o objetivo do trabalho foi avaliar e comparar o desempenho de três estratégias de aeração de milho armazenado quanto à ocorrência de fungos e à condutividade elétrica dos grãos.

\section{Material e MÉTOdos}

Foram utilizados seis silos de pequena escala, construídos a partir de tambores de óleo diesel com dimensões de 0,57 $\mathrm{m}$ de diâmetro e $0,85 \mathrm{~m}$ de altura, com isolamento externo de poliestireno expandido (isopor) de $0,01 \mathrm{~m}$ de espessura. Os silos possuíam aberturas laterais ao longo da altura, para a retirada de amostras posicionadas nas alturas $0,31,0,53$ e 0,74 $\mathrm{m}$ em relação à base.

A aeração foi realizada por microventiladores elétricos axiais da marca Qualitas, modelo Q40SD4, vazão máxima 3,0 $\pm 5 \% \mathrm{~L} \mathrm{~s}^{-1}$, pressão máxima 3,0 mmca, potência nominal 1,2 W. Um inversor de frequência foi utilizado para variar a rotação do ventilador e ajustar a vazão de ar aos valores de projeto, ou seja, $0,01 \mathrm{~m}^{3}$ min $^{-1}$ para o milho seco $(11 \%)$ e $0,08 \mathrm{~m}^{3} \mathrm{~min}^{-1}$ para o milho úmido $(17 \%)$.

Realizaram-se dois ensaios de aeração com duração de 24 dias. No primeiro ensaio utilizaram-se lotes de milho seco e úmido, armazenados em seis silos: três com milho seco (Ui=11\% b.u.) e outros três com milho úmido ( $\mathrm{Ui}=17 \%$ b.u.); o ensaio com milho seco ocorreu de 12 de agosto a 04 de setembro de 2009 e com milho úmido, de 17 de agosto a 10 de setembro de 2009.

O segundo ensaio foi realizado apenas com milho seco ( $\mathrm{Ui}=11 \%$ b.u.) e a ele se acrescentou um silo controle, sem aeração. Este ensaio foi realizado no período de 24 de outubro a 17 de novembro de 2009. 
Os lotes de milho úmido foram obtidos com adição de água e revolvimento frequente da massa de grãos durante período de 4 dias, em câmara com temperatura de $16{ }^{\circ} \mathrm{C}$. A massa de água acrescentada foi calculada a partir dos valores de umidade inicial e final dos grãos. Embora a expressão "milho úmido" não seja a mais adequada em razão do procedimento utilizado, esta terminologia será utilizada no texto para facilitar sua identificação.

Antes de serem levados aos silos os grãos foram aquecidos visando simular o processo de aquecimento espontâneo que pode ocorrer durante a armazenagem. Sacos plásticos pretos contendo $10 \mathrm{~kg}$ de grãos (camada de $0,08 \mathrm{~m}$ ) foram expostos ao sol e movimentados periodicamente até alcançarem temperatura de $40^{\circ} \mathrm{C}$. A elevação da temperatura foi acompanhada por termômetros.

Os tratamentos de aeração foram: aeração contínua, aeração noturna e aeração em condições de umidade de equilíbrio entre o ar ambiente e os grãos.

$\mathrm{Na}$ aeração contínua o sistema operou ininterruptamente durante 24 dias e, na aeração noturna, um temporizador realizava o acionamento automático do ventilador, das $20 \mathrm{~h}$ de um dia às 6 h do dia seguinte. Na aeração em condições de equilíbrio o sistema era acionado por um umidostato apenas quando a umidade relativa do ar ambiente estava em condições de equilíbrio com a umidade do grão, ou seja, para milho seco (11\%) na faixa de umidade relativa de 68 a $72 \%$ e na faixa de 83 a $87 \%$, para milhoúmido (17\%).

Empregaram-se duas metodologias na contagem de fungos: a contagem de colônias por plaqueamento em superfície e o teste do papel de filtro (Blotter Test). Essas análises foram realizadas com cinco e três repetições, respectivamente, cujas amostras foram retiradas no primeiro dia e a cada seis dias durante o ensaio, totalizando cinco análises por ensaio.

A contagem de fungos por plaqueamento em superfície foi realizada no primeiro ensaio, em grãos de milho secos e úmidos, de acordo com a seguinte metodologia.

A amostra para plaqueamento foi preparada com a adição de $25 \mathrm{~g}$ de milho moído em $225 \mathrm{~mL}$ de água peptonada tamponada (diluição 1:10 ou 10 $0^{-1}$ ). Os tubos de diluição foram preparados com $9 \mathrm{~mL}$ de água destilada e esterilizada. As amostras foram diluídas até a diluição 1:100 $\left(10^{-2}\right)$. Alíquotas de $0,1 \mathrm{~mL}$ das diluições foram transferidas para cinco placas de Petri com o meio de cultura ágar batata dextrose com cloranfenicol. As placas foram incubadas em estufa a $25^{\circ} \mathrm{C}$, por $72 \mathrm{~h}$, após o que se procedeu à contagem de unidades formadoras de colônias (UFC), por meio da identificação dos seus aspectos macroscópico e microscópico (Ribeiro et al., 2003), identificando as colônias de Aspergillus spp., Fusarium spp. e Penicillium spp.

No cálculo dos resultados multiplicou-se a quantidade de UFC $\mathrm{g}^{-1}$ pelo inverso da diluição. No caso da diluição $10^{-1}$, multiplicou-se por $10^{1} \mathrm{e}$, na $10^{-2}$, por $10^{2}$. O resultado final foi multiplicado por $10(\mathrm{dez})$, para levar em conta o volume 10 vezes menor (que $1 \mathrm{~mL}$ ) inoculado. Quando não se observou crescimento de algum dos fungos nas placas considerou-se o número de colônias da primeira diluição inoculada como sendo 1 e se calculou o resultado, como já referido; relatou-se, então, o resultado final como menor do que o obtido no cálculo, valor estimado (Silva et al., 2007).
O teste do papel de filtro (Blotter Test) com congelamento foi aplicado no segundo ensaio em grãos secos de milho. Os grãos foram colocados devidamente espaçados, em recipientes gerbox contendo uma folha de papel germiteste umedecida com água destilada. Foram mantidos, durante $24 \mathrm{~h}$, em temperatura de $20^{\circ} \mathrm{C}$ e fotoperíodo de $12 / 12 \mathrm{~h}$ de escuro e luz fluorescente branca de $40 \mathrm{~W}$ em câmara de incubação B.O.D. Para inibir a germinação dos grãos, eles foram congelados durante $24 \mathrm{~h}$; decorrido este período, retornaram à câmara de incubação durante oito dias. Os grãos foram analisados individualmente em microscópio estereoscópico e, quando necessário, examinadas lâminas ao microscópio composto, detectando-se a presença dos fungos Aspergillus spp., Penicillium spp. e Fusarium spp. O resultado foi dado em porcentagem numérica de grãos de milho infectados com cada fungo (Machado, 1988).

A determinação da condutividade elétrica seguiu a metodologia adaptada da proposta pela AOSA (1983). Pesaramse aproximadamente $10 \mathrm{~g}$ de milho e se adicionaram $80 \mathrm{~mL}$ de água deionizada. As amostras foram mantidas em câmara de incubação por 24 h a $25^{\circ} \mathrm{C}$ para embebição; após este período a solução foi agitada e filtrada para a leitura em condutivímetro da marca Digimed, modelo DM-31. Esta análise foi realizada em triplicata e o resultado expresso em $\mu \mathrm{S} \mathrm{cm}^{-1}$.

\section{RESULTADOS E DISCUSSÃO}

Os resultados apresentados nas Tabelas 1 e 2 incluem valores de contagem das diluições $10^{-1}$ e $10^{-2}$; este último se encontra identificado por *. Na análise 5 da amostra de milho úmido retirada da altura inferior $(0,31 \mathrm{~m})$ do silo de aeração noturna, não foi possível realizar a leitura das placas uma vez que todas elas estavam infestadas com um fungo que não era de interesse deste trabalho.

Pela análise da Tabela 1 vê-se que o Aspergillus spp. praticamente não foi observado em milho seco enquanto em grãos úmidos (Tabela 2), se observou desenvolvimento desse fungo em todas as estratégias de aeração, destacando-se a altura superficial $(0,74 \mathrm{~m})$. As menores ocorrências de Aspergillus spp. se deram nos silos de aeração contínua e noturna, ambos na altura inferior $(0,31 \mathrm{~m})$ devido, provavelmente, à secagem que ocorreu nessas alturas durante o ensaio, reduzindo o teor de umidade em cerca de 3 e $2 \%$, respectivamente.

Quanto aos resultados do fungo Penicillium spp. em milho seco (Tabela 1), notou-se comportamento similar na maioria das alturas dos silos. Do início (análise 1) até o meio do ensaio (análise 3) as contagens demonstraram tendência de redução e, a partir do meio ao final do ensaio (análise 5), os valores de contagem indicaram crescimento.

Em relação aos grãos úmidos (Tabela 2), observou-se comportamento predominante de elevação do número de colônias de Penicillium spp. durante o ensaio. O silo de aeração em condições de umidade de equilíbrio foi o que apresentou maiores contagens nas três alturas, ao final do período de aeração. Ribeiro et al. (2003) classificaram o Penicillium spp. como fungo dominante em produtos originados do milho. 
Tabela 1. Contagem dos fungos Aspergillus, Penicillium e Fusarium (U FC $\left.{ }^{-1}\right)$ obtida a partir de três alturas dos silos submetidos à aeração contínua, noturna e em condições de equilíbrio durante 24 dias de armazenamento de milho seco (Ensaio 1)

\begin{tabular}{|c|c|c|c|c|c|c|c|}
\hline \multicolumn{8}{|c|}{ Unidades formadoras de colônias $\left(\mathrm{UFC}^{-1}\right) \times 10^{2}$} \\
\hline Estratégia & Altura (m) & Fungo & Dia zero & 6 dias & 12 dias & 18 dias & 24 dias \\
\hline \multirow{3}{*}{ Contínua } & 0,74 & $\begin{array}{l}\text { Aspergillus } \\
\text { Penicillium } \\
\text { Fusarium }\end{array}$ & $\begin{array}{r}<10^{2} \\
7,75 \times 10^{2} \\
5,25 \times 10^{2}\end{array}$ & $\begin{array}{r}<10^{2} \\
4,9 \times 10^{3} \\
<10^{2}\end{array}$ & $\begin{array}{r}<10^{2} \\
<10^{2} \\
1,1 \times 10^{4}\end{array}$ & $\begin{array}{r}3 \times 10^{2} \\
3,6 \times 10^{2} \\
3,5 \times 10^{4}\end{array}$ & $\begin{array}{r}<10^{2} \\
3,7 \times 10^{3} \\
3,2 \times 10^{2}\end{array}$ \\
\hline & 0,53 & $\begin{array}{l}\text { Aspergillus } \\
\text { Penicillium } \\
\text { Fusarium }\end{array}$ & $\begin{array}{r}<10^{2} \\
2,76 \times 10^{3} \\
1,42 \times 10^{3}\end{array}$ & $\begin{array}{r}<10^{2} \\
3,4 \times 10^{2} \\
7,64 \times 10^{3}\end{array}$ & $\begin{array}{r}<10^{2} \\
<10^{2} \\
3,82 \times 10^{3}\end{array}$ & $\begin{array}{r}<10^{2} \\
5,5 \times 10^{2} \\
5,8 \times 10^{3} \\
\end{array}$ & $\begin{array}{r}<10^{2} \\
3,4 \times 10^{3} \\
7 \times 10^{2} \\
\end{array}$ \\
\hline & 0,31 & $\begin{array}{l}\text { Aspergillus } \\
\text { Penicillium } \\
\text { Fusarium }\end{array}$ & $\begin{array}{r}<10^{2} \\
2,06 \times 10^{3} \\
<10^{2}\end{array}$ & $\begin{array}{r}<10^{2} \\
<10^{2} \\
2,75 \times 10^{3}\end{array}$ & $\begin{array}{r}<10^{2} \\
<10^{2} \\
4,0 \times 10^{2}\end{array}$ & $\begin{array}{r}<10^{2} \\
1,02 \times 10^{2} \\
3,32 \times 10^{3} \\
\end{array}$ & $\begin{array}{r}<10^{2} \\
3,54 \times 10^{3} \\
9,2 \times 10^{2}\end{array}$ \\
\hline \multirow{3}{*}{ Noturna } & 0,74 & $\begin{array}{l}\text { Aspergillus } \\
\text { Penicillium } \\
\text { Fusarium }\end{array}$ & $\begin{array}{r}<10^{2} \\
3,08 \times 10^{3} \\
8,80 \times 10^{3} \\
\end{array}$ & $\begin{array}{r}<10^{2} \\
4,25 \times 10^{3} \\
1,7 \times 10^{3}\end{array}$ & $\begin{array}{r}<10^{2} \\
<10^{2} \\
2,52 \times 10^{3}\end{array}$ & $\begin{array}{r}<10^{2} * \\
<10^{2} * \\
2,72 \times 10^{5} *\end{array}$ & $\begin{array}{r}<10^{2} \\
2,1 \times 10^{3} \\
1,4 \times 10^{3} \\
\end{array}$ \\
\hline & 0,53 & $\begin{array}{l}\text { Aspergillus } \\
\text { Penicillium } \\
\text { Fusarium }\end{array}$ & $\begin{array}{r}<10^{2} \\
7,75 \times 10^{2} \\
<10^{2}\end{array}$ & $\begin{array}{r}<10^{2} \\
<10^{2} \\
3,8 \times 10^{2}\end{array}$ & $\begin{array}{r}<10^{2} \\
<10^{2} \\
1,34 \times 10^{3}\end{array}$ & $\begin{array}{r}<10^{2} \\
1,26 \times 10^{3} \\
5,4 \times 10^{2} \\
\end{array}$ & $\begin{array}{r}<10^{2} \\
3,82 \times 10^{3} \\
4,2 \times 10^{3}\end{array}$ \\
\hline & 0,31 & $\begin{array}{l}\text { Aspergillus } \\
\text { Penicillium } \\
\text { Fusarium }\end{array}$ & $\begin{array}{r}<10^{2} \\
1,15 \times 10^{4} \\
<10^{2}\end{array}$ & $\begin{array}{r}<10^{2} \\
1,6 \times 10^{2} \\
6,82 \times 10^{3} \\
\end{array}$ & $\begin{array}{l}<10^{2} \\
<10^{2} \\
2 \times 10^{2}\end{array}$ & $\begin{array}{r}<10^{2} \\
2,7 \times 10^{3} \\
1,1 \times 10^{3}\end{array}$ & $\begin{array}{r}<10^{2} \\
4,4 \times 10^{3} \\
1,36 \times 10^{3}\end{array}$ \\
\hline \multirow{3}{*}{ Equilíbrio } & 0,74 & $\begin{array}{l}\text { Aspergillus } \\
\text { Penicillium } \\
\text { Fusarium }\end{array}$ & $\begin{array}{r}<10^{2} * \\
9,2 \times 10^{3} * \\
6,96 \times 10^{4} *\end{array}$ & $\begin{array}{r}<10^{2} * \\
6,8 \times 10^{3} * \\
4,16 \times 10^{4} * \\
\end{array}$ & $\begin{array}{r}<10^{2} \\
4,8 \times 10^{2} \\
4,21 \times 10^{4} \\
\end{array}$ & $\begin{array}{l}2,4 \times 10^{2} \\
9,2 \times 10^{2} \\
4,4 \times 10^{4} \\
\end{array}$ & $\begin{array}{r}<10^{2 *} \\
4,4 \times 10^{3} * \\
1,84 \times 10^{5} * \\
\end{array}$ \\
\hline & 0,53 & $\begin{array}{l}\text { Aspergillus } \\
\text { Penicillium } \\
\text { Fusarium }\end{array}$ & $\begin{array}{l}<10^{2} \\
8 \times 10^{2} \\
<10^{2} \\
\end{array}$ & $\begin{array}{r}<10^{2} * \\
3,45 \times 10^{4} * \\
<10^{2} *\end{array}$ & $\begin{array}{r}<10^{2} \\
<10^{2} \\
1,23 \times 10^{5} \text { est }\end{array}$ & $\begin{array}{r}<10^{2} \\
6,1 \times 10^{3} \\
8,6 \times 10^{2} \\
\end{array}$ & $\begin{array}{r}<10^{2} \\
2,78 \times 10^{3} \\
7,5 \times 10^{3} \\
\end{array}$ \\
\hline & 0,31 & $\begin{array}{l}\text { Aspergillus } \\
\text { Penicillium } \\
\text { Fusarium }\end{array}$ & $\begin{array}{r}<10^{2} \\
1,84 \times 10^{3} \\
3,80 \times 10^{2}\end{array}$ & $\begin{array}{r}<10^{2} * \\
<10^{2} * \\
1,16 \times 10^{6} *\end{array}$ & $\begin{array}{r}<10^{2} \\
<10^{2} \\
1,33 \times 10^{4}\end{array}$ & $\begin{array}{r}<10^{2} \\
4,2 \times 10^{2} \\
3,46 \times 10^{3}\end{array}$ & $\begin{array}{r}<10^{2} \\
1,9 \times 10^{3} \\
1,7 \times 10^{3}\end{array}$ \\
\hline
\end{tabular}

* Contagem realizada na diluição $10^{-2}$

Analisando-se, agora, o Fusarium spp. em milho seco, observa-se maior ocorrência desse fungo nas alturas superficiais $(0,74 \mathrm{~m})$ do que nas demais e que a estratégia de aeração em condições de umidade de equilíbrio apresentou maiores contagens durante todo o período de aeração. Ribeiro et al. (2003) verificaram que o Fusarium spp. moniliforme ocorreu com frequência em subprodutos do milho. Pinto et al. (2007) detectaram ocorrência de Fusarium subglutinans entre 50 a $99 \%$ das amostras de 36 diferentes cultivares de milho estudadas.

Nos grãos úmidos notou-se, majoritariamente, tendência de redução da ocorrência de Fusarium spp. ao longo do ensaio.

Ressalta-se que a ocorrência do fungo Fusarium spp. em grãos secos foi superior à observada em grãos úmidos.

Ao final do ensaio obtiveram-se imagens para ilustrar o grau de infestação dos grãos visto que o desenvolvimento de fungos nos grãos úmidos foi tão intenso que, visualmente, era possível observá-los (Figura 1). Também durante a descarga dos silos, realizada manualmente, foi possível constatar, visualmente, o estado de conservação dos grãos: aqueles aerados secos não apresentavam alteração de cor e odor; todavia, os armazenados úmidos estavam esverdeados e, quando revolvidos, provocavam poeira com odor desagradável. Notou-se também que uma pequena altura de grãos aerados secos localizada na parte inferior dos silos, próxima à chapa perfurada, se apresentava com coloração normal.
A. Milho seco

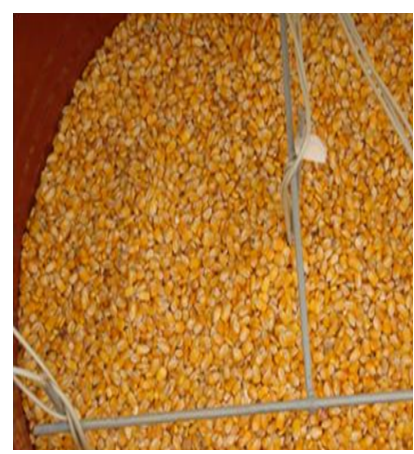

B. Milho úmido

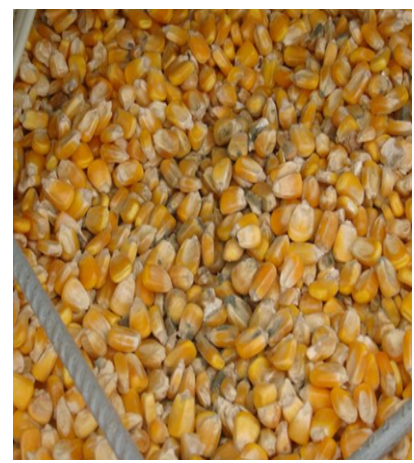

Figura 1. Grãos de milho secos (A) e úmidos (B) após 24 dias de armazenamento com aeração (Ensaio 1) 
Tabela 2. Contagem dos fungos Aspergillus, Penicillium e Fusarium (U FC $\left.{ }^{-1}\right)$ obtida a partir de três alturas dos silos submetidos à aeração contínua, noturna e em condições de equilíbrio durante 24 dias de armazenamento de milho úmido (Ensaio 1)

\begin{tabular}{|c|c|c|c|c|c|c|c|}
\hline \multicolumn{8}{|c|}{ Unidades formadoras de colônias (UFC $\mathrm{g}^{-1}$ ) $\times 10^{2}$} \\
\hline Estratégia & Altura (m) & Fungo & Dia zero & 6 dias & 12 dias & 18 dias & 24 dias \\
\hline \multirow{3}{*}{ Contínua } & 0,74 & $\begin{array}{l}\text { Aspergillus } \\
\text { Penicillium } \\
\text { Fusarium }\end{array}$ & $\begin{array}{r}<10^{2} \\
4,4 \times 10^{2} \\
<10^{2}\end{array}$ & $\begin{array}{r}<10^{2} * \\
<10^{2} * \\
1,8 \times 10^{6} *\end{array}$ & $\begin{array}{r}6,42 \times 10^{3} \\
<10^{2} \\
<10^{2}\end{array}$ & $\begin{array}{r}1,3 \times 10^{4} * \\
8,52 \times 10^{4} * \\
6,8 \times 10^{3} *\end{array}$ & $\begin{array}{r}3,38 \times 10^{4} * \\
3,48 \times 10^{4} * \\
<10^{2} *\end{array}$ \\
\hline & 0,53 & $\begin{array}{l}\text { Aspergillus } \\
\text { Penicillium } \\
\text { Fusarium } \\
\end{array}$ & $\begin{array}{r}<10^{2} \\
1,6 \times 10^{2} \\
2,54 \times 10^{3} \\
\end{array}$ & $\begin{array}{r}3 \times 10^{2} \\
7,2 \times 10^{2} \\
9,4 \times 10^{2} \\
\end{array}$ & $\begin{array}{r}3 \times 10^{2} \\
5,8 \times 10^{2} \\
<10^{2} \\
\end{array}$ & $\begin{array}{r}2,25 \times 10^{2} \\
2,33 \times 10^{3} \\
<10^{2} \\
\end{array}$ & $\begin{array}{r}2,78 \times 10^{3} \\
6,54 \times 10^{3} \\
<10^{2} \\
\end{array}$ \\
\hline & 0,31 & $\begin{array}{l}\text { Aspergillus } \\
\text { Penicillium } \\
\text { Fusarium }\end{array}$ & $\begin{array}{r}<10^{2} \\
2,72 \times 10^{3} \\
3,12 \times 10^{3}\end{array}$ & $\begin{array}{l}<10^{2} \\
<10^{2} \\
<10^{2}\end{array}$ & $\begin{array}{r}5,8 \times 10^{2} \\
2 \times 10^{2} \\
2,6 \times 10^{2} \\
\end{array}$ & $\begin{array}{r}<10^{2} \\
2,42 \times 10^{3} \\
2,34 \times 10^{3}\end{array}$ & $\begin{array}{r}3,2 \times 10^{2} \\
1,18 \times 10^{3} \\
1,2 \times 10^{2}\end{array}$ \\
\hline \multirow{3}{*}{ Noturna } & 0,74 & $\begin{array}{l}\text { Aspergillus } \\
\text { Penicillium } \\
\text { Fusarium }\end{array}$ & $\begin{array}{r}<10^{2} \\
3 \times 10^{2} \\
1,37 \times 10^{3} \\
\end{array}$ & $\begin{array}{r}1,1 \times 10^{3} \\
8,2 \times 10^{2} \\
<10^{2} \\
\end{array}$ & $\begin{array}{r}3,2 \times 10^{2} \\
5,6 \times 10^{2} \\
<10^{2} \\
\end{array}$ & $\begin{array}{r}<10^{2} * \\
6,1 \times 10^{4} * \\
<10^{2} *\end{array}$ & $\begin{array}{r}4,1 \times 10^{3} \\
1,64 \times 10^{3} \\
<10^{2}\end{array}$ \\
\hline & 0,53 & $\begin{array}{l}\text { Aspergillus } \\
\text { Penicillium } \\
\text { Fusarium }\end{array}$ & $\begin{array}{r}<10^{2} \\
<10^{2} \\
2,53 \times 10^{3} \\
\end{array}$ & $\begin{array}{r}<10^{2} \\
<10^{2} \\
3,8 \times 10^{2} \\
\end{array}$ & $\begin{array}{r}<10^{2} \\
6,5 \times 10^{2} \\
<10^{2} \\
\end{array}$ & $\begin{array}{r}<10^{2} * \\
2,24 \times 10^{4} * \\
<10^{2} *\end{array}$ & $\begin{array}{r}6 \times 10^{2} \\
3,42 \times 10^{3} \\
<10^{2} \\
\end{array}$ \\
\hline & 0,31 & $\begin{array}{l}\text { Aspergillus } \\
\text { Penicillium } \\
\text { Fusarium }\end{array}$ & $\begin{array}{r}<10^{2} \\
3,67 \times 10^{2} \\
<10^{2}\end{array}$ & $\begin{array}{r}<10^{2} \\
<10^{2} \\
6,6 \times 10^{2}\end{array}$ & $\begin{array}{r}<10^{2} \\
2,2 \times 10^{2} \\
1,14 \times 10^{3}\end{array}$ & $\begin{array}{r}3 \times 10^{2} \\
2,96 \times 10^{3} \\
<10^{2}\end{array}$ & - \\
\hline \multirow{3}{*}{ Equilíbrio } & 0,74 & $\begin{array}{l}\text { Aspergillus } \\
\text { Penicillium } \\
\text { Fusarium }\end{array}$ & $\begin{array}{r}<10^{2} \\
3,34 \times 10^{3} \\
<10^{2}\end{array}$ & $\begin{array}{l}<10^{2} * \\
<10^{2} * \\
7 \times 10^{3} *\end{array}$ & $\begin{array}{l}1,2 \times 10^{2} \\
7,2 \times 10^{2} \\
2,8 \times 10^{2}\end{array}$ & $\begin{array}{r}1,48 \times 10^{3} \\
5,76 \times 10^{3} \\
<10^{2}\end{array}$ & $\begin{array}{l}7,67 \times 10^{4} * \\
1,13 \times 10^{4} * \\
1,33 \times 10^{3} *\end{array}$ \\
\hline & 0,53 & $\begin{array}{l}\text { Aspergillus } \\
\text { Penicillium } \\
\text { Fusarium }\end{array}$ & $\begin{array}{r}<10^{2} \\
1,8 \times 10^{2} \\
<10^{2}\end{array}$ & $\begin{array}{r}2 \times 10^{2} \\
1,4 \times 10^{2} \\
<10^{2} \\
\end{array}$ & $\begin{array}{r}5,4 \times 10^{2} \\
7,4 \times 10^{2} \\
<10^{2} \\
\end{array}$ & $\begin{array}{r}1,16 \times 10^{4} * \\
3,24 \times 10^{4} * \\
<10^{2} * \\
\end{array}$ & $\begin{array}{r}6,44 \times 10^{4} * \\
1,7 \times 10^{4} * \\
<10^{2} *\end{array}$ \\
\hline & 0,31 & $\begin{array}{l}\text { Aspergillus } \\
\text { Penicillium } \\
\text { Fusarium }\end{array}$ & $\begin{array}{r}<10^{2} \\
1,3 \times 10^{3} \\
3,75 \times 10^{2}\end{array}$ & $\begin{array}{r}<10^{2} \\
<10^{2} \\
6,4 \times 10^{2}\end{array}$ & $\begin{array}{r}<10^{2} \\
6,9 \times 10^{3} \\
3,8 \times 10^{2}\end{array}$ & $\begin{array}{l}5,4 \times 10^{3} * \\
2,5 \times 10^{4} * \\
<10^{2} *\end{array}$ & $\begin{array}{r}1,86 \times 10^{4} * \\
4,03 \times 10^{4} * \\
<10^{2} *\end{array}$ \\
\hline
\end{tabular}

* Contagem realizada na diluição $10^{-2}$

Observa-se, na Tabela 3, que no silo com aeração em condições de equilíbrio a ocorrência do fungo Aspergillus spp. foi igual entre as alturas enquanto nos demais a altura de 0,53 $\mathrm{m}$ se destacou com maior ocorrência desse fungo. Em relação ao Penicillium spp., observou-se igualdade de ocorrência entre as alturas nos três silos com milho seco. Verifica-se, ainda, que a aeração noturna e em condições de umidade de equilíbrio apresentou homogeneidade entre as alturas quanto à ocorrência

Tabela 3. Teste de Tukey para comparação da contagem de Aspergillus spp., Penicillium spp. e Fusarium spp. entre as alturas dos silos com aeração contínua, noturna e em condições de umidade de equilíbrio de milho seco do ensaio 2

\begin{tabular}{ccccc}
\hline \multirow{2}{*}{ Fungos } & Altura & \multicolumn{3}{c}{ Porcentagem numérica de grãos infectados (\%) } \\
\cline { 3 - 5 } & $(\mathbf{m})$ & Contínua & Noturna & Equilíbrio \\
\multirow{4}{*}{ Aspergillus } & 0,74 & $6,50 \mathrm{~b}$ & $6,25 \mathrm{~b}$ & $11,51 \mathrm{a}$ \\
& 0,53 & $37,11 \mathrm{a}$ & $52,44 \mathrm{a}$ & $12,76 \mathrm{a}$ \\
& 0,31 & $10,08 \mathrm{~b}$ & $12,88 \mathrm{~b}$ & $11,52 \mathrm{a}$ \\
\hline \multirow{3}{*}{ Penicillium } & 0,74 & $86,45 \mathrm{a}$ & $75,52 \mathrm{a}$ & $73,60 \mathrm{a}$ \\
& 0,53 & $87,41 \mathrm{a}$ & $78,44 \mathrm{a}$ & $74,83 \mathrm{a}$ \\
& 0,31 & $76,13 \mathrm{a}$ & $76,50 \mathrm{a}$ & $77,52 \mathrm{a}$ \\
\hline \multirow{2}{*}{ Fusarium } & 0,74 & $93,50 \mathrm{ab}$ & $95,50 \mathrm{a}$ & $89,37 \mathrm{a}$ \\
& 0,53 & $92,34 \mathrm{~b}$ & $90,22 \mathrm{a}$ & $91,50 \mathrm{a}$ \\
& 0,31 & $98,00 \mathrm{a}$ & $94,00 \mathrm{a}$ & $92,91 \mathrm{a}$ \\
\hline
\end{tabular}

Médias seguidas da mesma letra na coluna não diferem entre si pelo teste de Tukey a $5 \%$ de probabilidade de Fusarium spp. Em relação à aeração contínua as alturas de $0,74 \mathrm{~m}$ (superior) e $0,53 \mathrm{~m}$ (intermediária) indicaram menor ocorrência de Fusarium spp.

Quando se realizou a comparação da ocorrência dos fungos Aspergillus spp., Penicillium spp. e Fusarium spp. entre os tratamentos observou-se, para todos eles, que não ocorreu diferença significativa entre as estratégias de aeração (Tabela 4).

Tabela 4. Teste de Tukey para comparação da ocorrência dos fungos A spergillus spp., Penicillium spp. e Fusarium spp. entre aeração contínua, noturna e em condições de umidade de equilíbrio de milho seco do ensaio 2

\begin{tabular}{cccc}
\hline \multicolumn{4}{c}{ Porcentagem numérica de grãos infectados (\%) } \\
\hline Estratégia & Aspergillus & Penicillium & Fusarium \\
Contínua & $17,90 \mathrm{a}$ & $83,33 \mathrm{a}$ & $94,61 \mathrm{a}$ \\
Noturna & $23,86 \mathrm{a}$ & $76,82 \mathrm{a}$ & $93,24 \mathrm{a}$ \\
Equilíbrio & $11,93 \mathrm{a}$ & $75,32 \mathrm{a}$ & $91,26 \mathrm{a}$ \\
\hline
\end{tabular}

Médias seguidas da mesma letra na coluna não diferem entre si pelo teste de Tukey a $5 \%$ de probabilidade

Verifica-se, a partir das Figuras 2, 3 e 4, que o Fusarium spp. apresentou contagens mais elevadas em todos os silos. O Penicillium spp., apresentava, nas primeiras análises, níveis inferiores ao Fusarium spp.; entretanto, durante o armazenamento demonstrou crescimento na maioria das alturas. O Aspergillus spp., por sua vez, obteve as menores porcentagens de contagem 
A. $0,74 \mathrm{~m}$

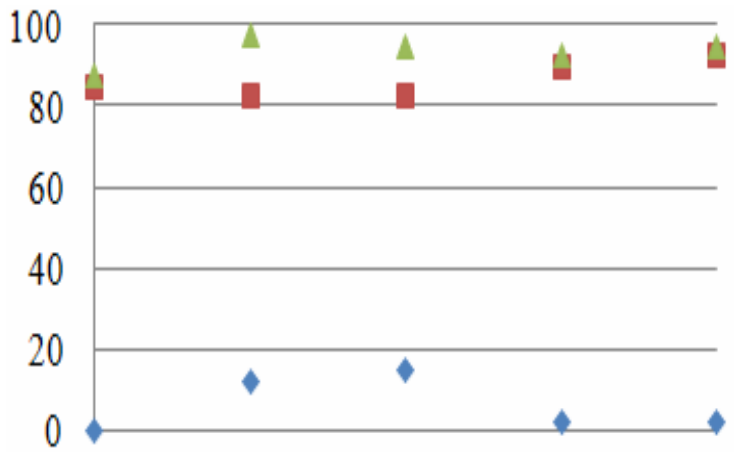

B. $0,53 \mathrm{~m}$

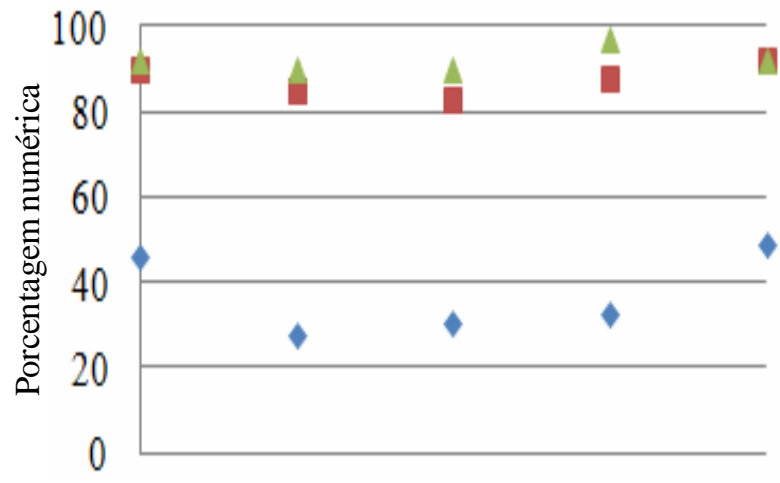

C. $0,31 \mathrm{~m}$

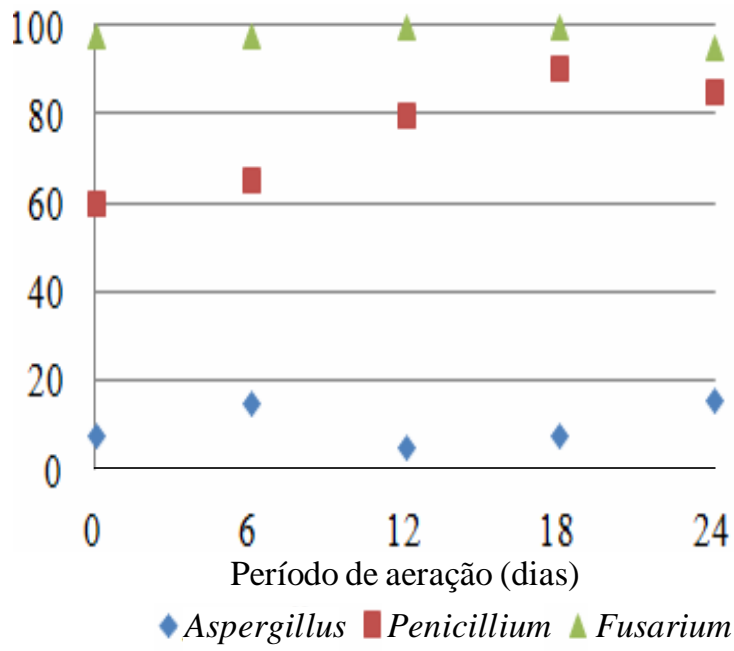

Figura 2. Porcentagem numérica de grãos de milho secos infectados com fungos Aspergillus, Penicillium e Fusarium nas alturas do silo de (A) 0,74 m, (B) 0,53 m e (C) 0,31 m durante aeração contínua (Ensaio 2)

e de maneira uniforme, sem crescimento, com exceção do silo com aeração noturna na altura de $0,53 \mathrm{~m}$, quando se verificou desenvolvimento elevado desse fungo.

Márcia \& Lazzari (1998) realizaram estudo com milho a granel, limpo e seco, grits e fubá, coletados diariamente por período de quatro meses de uma empresa processadora e constataram contaminação fúngica elevada nos grãos, correspondente a $82,7 \%$ das amostras contaminadas com Penicillim spp., 100\% com Aspergillus spp. e 97,5\% com Fusarium spp.

Os resultados encontrados por Antonello et al. (2009) indicam desenvolvimento dos fungos Aspergillus spp.,
A. $0,74 \mathrm{~m}$
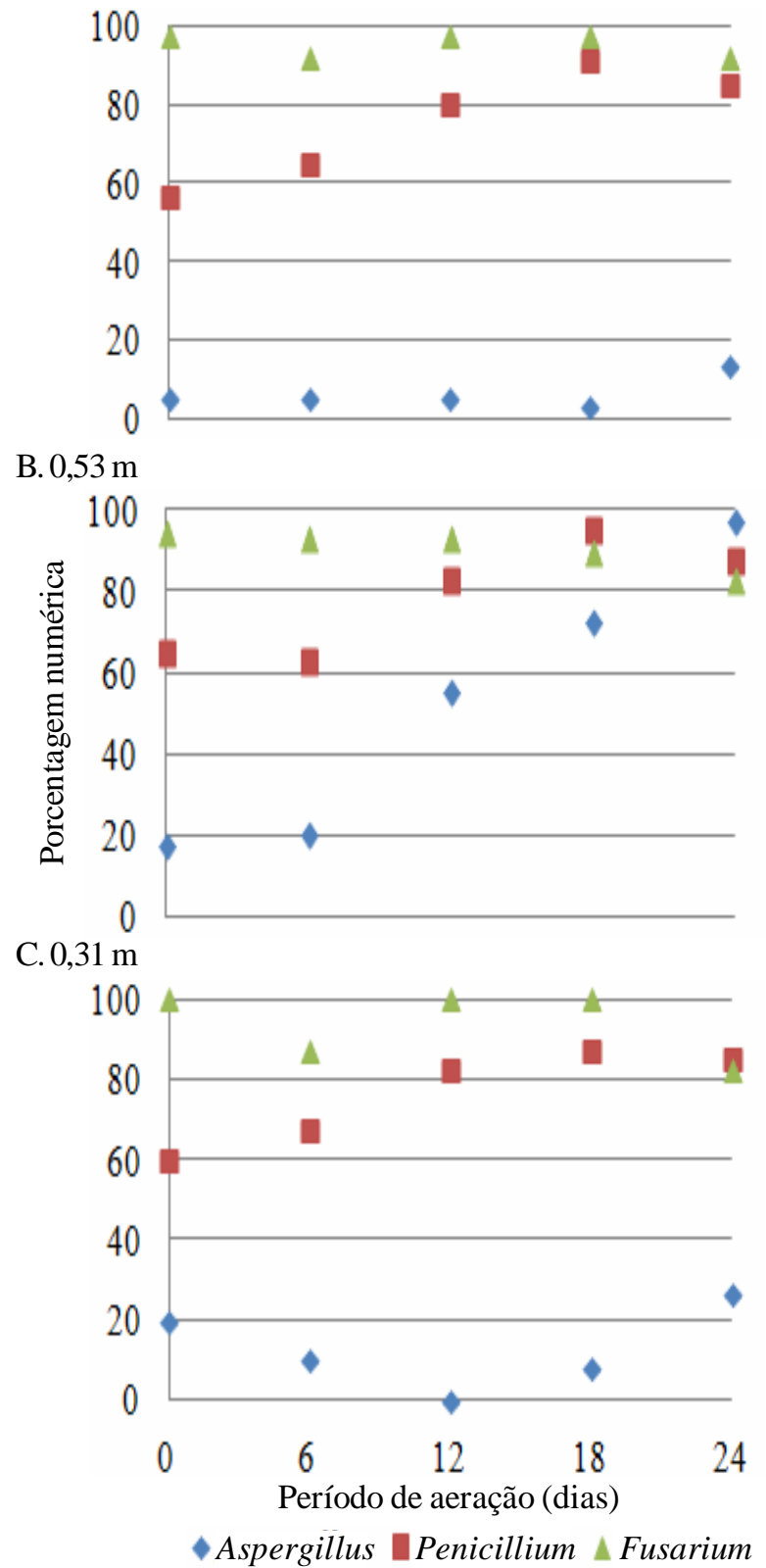

Figura 3. Porcentagem numérica de grãos de milho secos infectados com fungos Aspergillus, Penicillium e Fusarium nas alturas do silo de (A) 0,74 m, (B) 0,53 m e (C) 0,31 $\mathrm{m}$ durante aeração noturna (Ensaio 2 )

Penicillium spp. e Fusarium spp. em grãos de milho armazenados; os autores realizaram armazenamento de milho seco durante seis meses e observaram que, inicialmente, a incidência de Aspergillus spp. foi baixa (2\%) mas, durante o armazenamento, apresentou crescimento, chegando a $46 \%$; em relação ao Penicillium spp., os autores constataram incidência elevada de 85 a $100 \%$ e, quanto ao Fusarium spp., crescimento de 30 a $80 \%$.

Fessel et al. (2003), avaliando a qualidade sanitária de sementes de milho pelo teste do papel de filtro, observaram aumento da ocorrência de Penicillium spp. em amostras coletadas durante as fases do beneficiamento, a saber: recepção, pré-limpeza posterior à mesa de gravidade; nas 
A. $0,74 \mathrm{~m}$

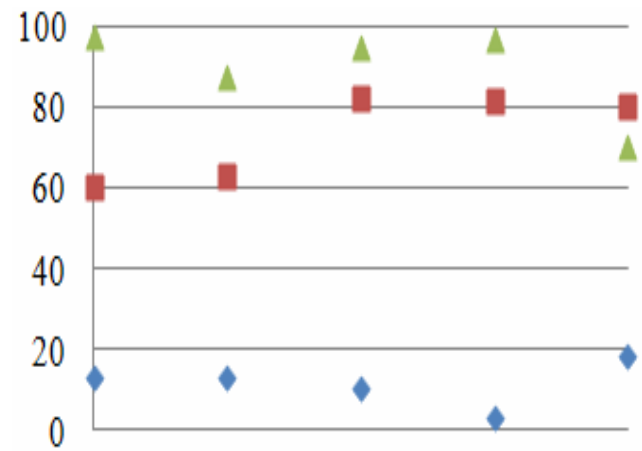

B. $0,53 \mathrm{~m}$

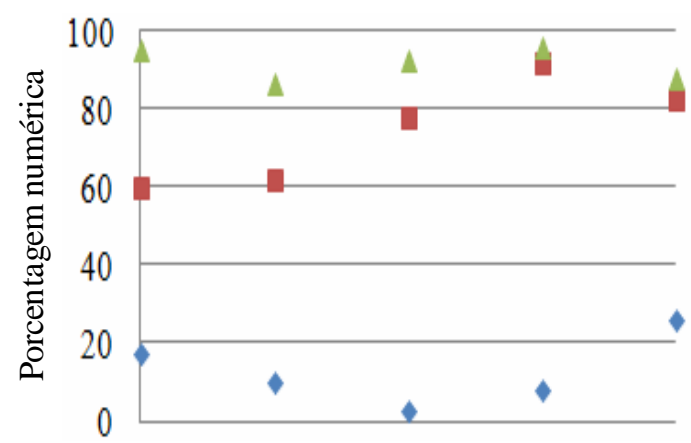

C. $0,31 \mathrm{~m}$

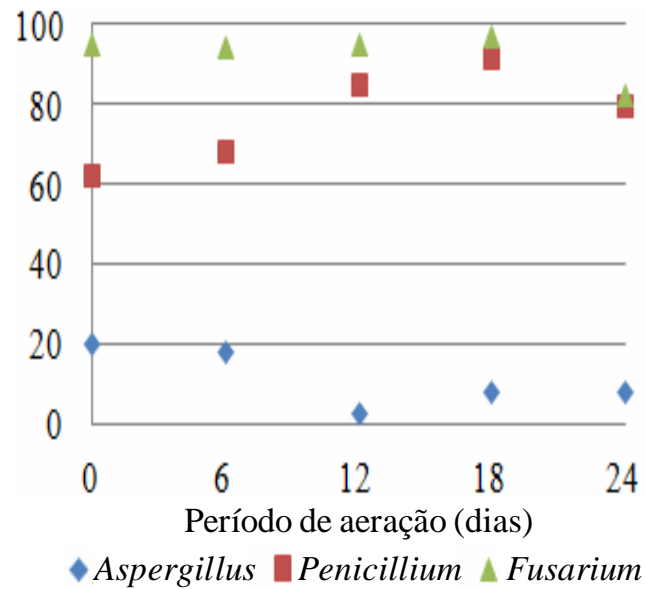

Figura 4. Porcentagem numérica de grãos de milho secos infectados com fungos A spergillus spp., Penicillium spp. e Fusarium spp. nas alturas do silo de (A) 0,74 m, (B) $0,53 \mathrm{~m}$ e (C) $0,31 \mathrm{~m}$ durante aeração em condições de umidade de equilíbrio (Ensaio 2)

fases seguintes, posteriores ao classificador e ao ensaque, a ocorrência desse fungo oscilou, com tendência de redução.

Observa-se, na Tabela 5, que na altura de $0,74 \mathrm{~m}$ em todas as estratégias de aeração a condutividade elétrica apresentou redução ao longo do período de ensaio; na altura de $0,53 \mathrm{~m}$ verificou-se, também, redução da condutividade elétrica no tempo, para as estratégias de aeração contínua e noturna enquanto na estratégia de aeração em condições de umidade de equilíbrio não se obteve diferença significativa entre as análises. Em referência à altura de $0,31 \mathrm{~m}$, verificou-se redução da condutividade elétrica na aeração contínua, da primeira para a segunda análise e, posteriormente, este valor se manteve uniforme até o final do ensaio, enquanto no silo de aeração noturna a condutividade elétrica permaneceu homogênea ao longo do tempo e, por fim, no silo de aeração

Tabela 5. Teste de Tukey para comparação da condutividade elétrica em três alturas do silo durante aeração contínua, noturna e em condições de umidade de equilíbrio com milho seco (Ensaio 1)

\begin{tabular}{ccccc}
\hline \multicolumn{5}{c}{ Condutividade elétrica $\left(\boldsymbol{\mu} \mathbf{S} \mathbf{~ c m}^{-1}\right)$} \\
\hline Altura & Tempo & \multicolumn{3}{c}{ Estratégia de aeração } \\
\cline { 3 - 5 }$(\mathbf{m})$ & (dias) & Contínua & Noturna & Equilíbrio \\
& 0 & $550,67 \mathrm{a}$ & $441,00 \mathrm{a}$ & $323,67 \mathrm{a}$ \\
& 6 & $414,67 \mathrm{ab}$ & $286,33 \mathrm{bc}$ & $233,67 \mathrm{ab}$ \\
0,74 & 12 & $417,67 \mathrm{ab}$ & $314,33 \mathrm{~b}$ & $207,33 \mathrm{ab}$ \\
& 18 & $382,67 \mathrm{ab}$ & $305,67 \mathrm{~b}$ & $253,67 \mathrm{ab}$ \\
& 24 & $263,67 \mathrm{ab}$ & $217,00 \mathrm{c}$ & $142,00 \mathrm{~b}$ \\
\hline \multirow{4}{*}{0,53} & 0 & $491,00 \mathrm{a}$ & $530,33 \mathrm{a}$ & $517,67 \mathrm{a}$ \\
& 6 & $393,00 \mathrm{ab}$ & $368,67 \mathrm{bc}$ & $370,67 \mathrm{a}$ \\
& 12 & $332,33 \mathrm{~b}$ & $356,67 \mathrm{bc}$ & $340,33 \mathrm{a}$ \\
& 18 & $377,67 \mathrm{ab}$ & $430,33 \mathrm{ab}$ & $387,00 \mathrm{a}$ \\
& 24 & $312,33 \mathrm{~b}$ & $264,33 \mathrm{c}$ & $326,00 \mathrm{a}$ \\
\hline \multirow{4}{*}{0,31} & 0 & $617,00 \mathrm{a}$ & $429,33 \mathrm{a}$ & $506,33 \mathrm{a}$ \\
& 6 & $336,00 \mathrm{~b}$ & $408,67 \mathrm{a}$ & $379,67 \mathrm{ab}$ \\
& 12 & $347,00 \mathrm{~b}$ & $370,00 \mathrm{a}$ & $353,67 \mathrm{ab}$ \\
& 18 & $356,33 \mathrm{~b}$ & $421,33 \mathrm{a}$ & $417,67 \mathrm{ab}$ \\
& 24 & $243,67 \mathrm{~b}$ & $268,00 \mathrm{a}$ & $337,33 \mathrm{~b}$ \\
\hline
\end{tabular}

Médias seguidas da mesma letra na coluna não diferem entre si pelo teste de Tukey a $5 \%$ de probabilidade

em condições de equilíbrio a redução foi significativa durante o ensaio.

De modo geral, a condutividade elétrica foi reduzida durante o ensaio com milho seco, em todas as estratégias de aeração estudadas.

Verificou-se, nos grãos úmidos ao longo do período, igualdade da condutividade elétrica na altura de $0,74 \mathrm{~m}$ nas estratégias de aeração contínua e noturna; todavia, na estratégia de aeração em condições de umidade de equilíbrio observou-se sua elevação. Em referência à altura de 0,53 m, com exceção da terceira análise do silo de aeração contínua e da quarta do silo de aeração noturna, a condutividade elétrica apresentou-se uniforme durante o período; entretanto, no silo de aeração em condições de equilíbrio notou-se elevação da condutividade ao final do ensaio e, na altura de $0,31 \mathrm{~m}$, elevação da condutividade elétrica em todas as estratégias de aeração, ao longo do ensaio (Tabela 6).

A análise global que se faz do comportamento da condutividade elétrica em milho úmido submetido à aeração, é que a estratégia de aeração em condições de equilíbrio se destacou por ser a que apresentou elevação da condutividade elétrica em todas as alturas do silo. Fessel et al. (2003) verificaram que a ocorrência de danos mecânicos propiciou aumento da condutividade elétrica em grãos de milho e, deste modo, a elevação da condutividade elétrica em grãos de milho pode ser devida a danos na estrutura das membranas celulares gerados por fungos.

Avaliou-se também o efeito global das estratégias de aeração sobre a condutividade elétrica média dos grãos secos e úmidos; a partir dos dados da Tabela 7 já não se verifica diferença 
Tabela 6. Teste de Tukey para comparação da condutividade elétrica em três alturas do silo durante aeração contínua, noturna e em condições de umidade de equilíbrio com milho úmido (Ensaio 1)

\begin{tabular}{ccccc}
\hline \multicolumn{5}{c}{ Condutividade elétrica $\left(\boldsymbol{\mu} \mathbf{S ~ c m}^{-1}\right.$ ) } \\
\hline Altura & Tempo & \multicolumn{3}{c}{ Estratégias de aeração } \\
\cline { 3 - 5 }$(\mathbf{m})$ & (dias) & Contínua & Noturna & Equilíbrio \\
& 0 & $253,00 \mathrm{a}$ & $317,33 \mathrm{a}$ & $356,67 \mathrm{abc}$ \\
0,74 & 6 & $383,33 \mathrm{a}$ & $263,67 \mathrm{a}$ & $305,67 \mathrm{c}$ \\
& 12 & $330,33 \mathrm{a}$ & $265,00 \mathrm{a}$ & $429,33 \mathrm{ab}$ \\
& 18 & $236,33 \mathrm{a}$ & $202,33 \mathrm{a}$ & $345,00 \mathrm{bc}$ \\
& 24 & $370,00 \mathrm{a}$ & $298,00 \mathrm{a}$ & $453,67 \mathrm{a}$ \\
\hline \multirow{4}{*}{0,53} & 0 & $329,00 \mathrm{~b}$ & $312,67 \mathrm{a}$ & $272,33 \mathrm{~b}$ \\
& 6 & $279,67 \mathrm{~b}$ & $291,00 \mathrm{a}$ & $309,00 \mathrm{~b}$ \\
& 12 & $605,67 \mathrm{a}$ & $296,67 \mathrm{a}$ & $350,00 \mathrm{~b}$ \\
& 18 & $221,33 \mathrm{~b}$ & $183,33 \mathrm{~b}$ & $361,33 \mathrm{~b}$ \\
& 24 & $368,33 \mathrm{~b}$ & $364,33 \mathrm{a}$ & $581,67 \mathrm{a}$ \\
\hline \multirow{2}{*}{0,31} & 0 & $278,33 \mathrm{ab}$ & $377,67 \mathrm{ab}$ & $330,67 \mathrm{ab}$ \\
& 6 & $232,33 \mathrm{ab}$ & $342,67 \mathrm{~b}$ & $365,67 \mathrm{ab}$ \\
& 12 & $320,00 \mathrm{ab}$ & $383,67 \mathrm{ab}$ & $417,33 \mathrm{a}$ \\
& 18 & $200,00 \mathrm{~b}$ & $268,67 \mathrm{~b}$ & $200,67 \mathrm{~b}$ \\
& 24 & $345,00 \mathrm{a}$ & $493,67 \mathrm{a}$ & $499,67 \mathrm{a}$ \\
\hline
\end{tabular}

Médias seguidas da mesma letra na coluna não diferem entre si pelo teste de Tukey a $5 \%$ de probabilidade

significativa da condutividade elétrica entre as estratégias de aeração.

Pode-se observar, na Tabela 8 , que na altura de $0,74 \mathrm{~m}$ os tratamentos de aeração noturna e controle proporcionaram valores uniformes da condutividade elétrica ao longo do período de ensaio; todavia, nas estratégias de aeração contínua e em condições de umidade de equilíbrio a condutividade elétrica apresentou crescimento ao final do ensaio. Em relação à altura de $0,53 \mathrm{~m}$, nota-se que no tratamento de aeração noturna a condutividade elétrica também se manteve igual entre as análises porém nos demais tratamentos houve elevação na condutividade ao longo do ensaio; na altura de $0,31 \mathrm{~m}$ o silo controle não apresentou diferença significativa na condutividade elétrica durante o ensaio enquanto nos tratamentos de aeração se observou sua elevação, ao final do ensaio.

Tabela 7. Teste de Tukey para comparação da condutividade elétrica entre as estratégias de aeração contínua, noturna e em condições de umidade de equilíbrio aplicadas em milho seco eúmido (Ensaio 1)

\begin{tabular}{ccc}
\hline \multicolumn{3}{c}{ Condutividade elétrica $\left(\boldsymbol{\mu} \mathbf{S} \mathbf{~ c m}^{-1}\right)$} \\
\hline Aeração & Milho seco & Milho úmido \\
Contínua & 389,04 a & 318,09 a \\
Noturna & 360,80 a & 331,20 a \\
Equilíbrio & 339,78 a & $350,18 \mathrm{a}$ \\
\hline
\end{tabular}

Médias seguidas da mesma letra na coluna não diferem entre si pelo teste de Tukey a $5 \%$ de probabilidade

Assim, os tratamentos de aeração noturna e o controle apresentaram maior uniformidade da condutividade elétrica ao longo do tempo, nas diferentes alturas da massa de grãos.

$\mathrm{Na}$ Tabela 9 se encontram as comparações dos valores médios de condutividade elétrica entre os tratamentos, podendo-se observar que entre as estratégias de aeração não houve diferença significativa.
Tabela 8. Teste de Tukey para comparação da condutividade elétrica em três alturas do silo durante aeração contínua, noturna, em condições de umidade de equilíbrio e no silo controle com milho seco (Ensaio 2)

\begin{tabular}{|c|c|c|c|c|c|}
\hline \multicolumn{6}{|c|}{ Condutividade elétrica $\left(\mu \mathrm{S} \mathrm{cm}^{-1}\right)$} \\
\hline \multirow{2}{*}{$\begin{array}{l}\text { Altura } \\
\text { (m) }\end{array}$} & \multirow{2}{*}{$\begin{array}{l}\text { Tempo } \\
\text { (dias) }\end{array}$} & \multicolumn{4}{|c|}{ Estratégias de aeração } \\
\hline & & Contínua & Noturna & Equilíbrio & Controle \\
\hline \multirow{5}{*}{0,74} & 0 & $174,18 a b$ & $192,50 \mathrm{a}$ & $178,28 \mathrm{~b}$ & $199,35 \mathrm{a}$ \\
\hline & 6 & $152,10 \mathrm{~b}$ & $151,48 a$ & $202,68 \mathrm{ab}$ & $189,90 \mathrm{a}$ \\
\hline & 12 & $152,25 b$ & $150,25 a$ & $162,48 \mathrm{~b}$ & 164,98 a \\
\hline & 18 & $167,48 \mathrm{~b}$ & $168,78 \mathrm{a}$ & $181,58 \mathrm{~b}$ & $154,60 \mathrm{a}$ \\
\hline & 24 & 247,15 a & 229,25 a & $261,75 \mathrm{a}$ & $186,95 \mathrm{a}$ \\
\hline \multirow{5}{*}{0,53} & 0 & $214,38 a b$ & $226,33 \mathrm{a}$ & $171,43 a b$ & $183,38 a b$ \\
\hline & 6 & $163,05 \mathrm{~b}$ & $194,08 \mathrm{a}$ & $200,03 a b$ & $177,35 a b$ \\
\hline & 12 & $160,88 \mathrm{~b}$ & 222,13 a & $153,08 \mathrm{~b}$ & $135,28 \mathrm{~b}$ \\
\hline & 18 & $195,43 a b$ & $218,75 \mathrm{a}$ & $166,45 a b$ & $194,75 a b$ \\
\hline & 24 & $250,08 \mathrm{a}$ & $267,50 \mathrm{a}$ & 227,43 a & $224,98 \mathrm{a}$ \\
\hline \multirow{5}{*}{0,31} & 0 & $166,08 \mathrm{ab}$ & $166,08 \mathrm{~b}$ & $209,43 a b$ & $200,30 a$ \\
\hline & 6 & $148,75 \mathrm{~b}$ & $156,75 b$ & $169,73 a b$ & $209,88 a$ \\
\hline & 12 & $147,58 b$ & 161,83 b & $163,18 b$ & $159,58 \mathrm{a}$ \\
\hline & 18 & 208,38 a & $190,88 \mathrm{ab}$ & $153,63 b$ & $195,70 \mathrm{a}$ \\
\hline & 24 & $213,65 a$ & $235,00 \mathrm{a}$ & $261,50 a$ & $240,25 a$ \\
\hline
\end{tabular}
probabilidade

Tabela 9. Teste de Tukey para comparação da condutividade elétrica entre os tratamentos de aeração contínua, noturna, em condições de umidade de equilíbrio e o silo controle aplicados a milho seco (Ensaio 2)

\begin{tabular}{cc}
\hline Condutividade elétrica $\left(\boldsymbol{\mu} \mathbf{S} \mathbf{c m}^{-1}\right)$ \\
Contínua & $184,09 \mathrm{a}$ \\
Noturna & $195,44 \mathrm{a}$ \\
Equilibrio & $190,84 \mathrm{a}$ \\
Controle & $187,81 \mathrm{a}$ \\
\hline
\end{tabular}

Médias seguidas da mesma letra na coluna não diferem entre si pelo teste de Tukey a $5 \%$ de probabilidade

\section{CONCLUSÕES}

1. Aspergillus: A eração contínua e noturna de milho seco, realizada no período de 12 de agosto a 04 de setembro de 2009, proporcionou a manutenção do número de unidades formadoras de colônias do fungo Aspergillus spp. na altura $0,31 \mathrm{~m}$; nos grãos úmidos nenhuma estratégia de aeração impediu o desenvolvimento desse fungo.

2. Penicillium: Nenhuma estratégia de aeração realizada no período de 17 de agosto a 10 de setembro de 2009 evitou o desenvolvimento de Penicillium na massa de grãos, tanto em milho seco como úmido.

3. Fusarium: Todas as estratégias de aeração aplicadas a grãos de milho secos e úmidos no período de 12 de agosto a 10 de setembro de 2009 permitiram o desenvolvimento de Fusarium nas alturas superficiais.

4. Todas as estratégias de aeração de milho seco realizada de 24 de outubro a 17 de novembro de 2009 não interferiram no desenvolvimento dos fungos Aspergillus spp., Penicillium spp. e Fusarium spp.: o Fusarium spp. apresentou contagens mais elevadas, o Penicillium spp. manifestou desenvolvimento e o Aspergillus spp. ocorreu com menor frequência. 
5. Condutividade elétrica: Todas as estratégias de aeração aplicadas ao milho seco no período entre 12 de agosto a 04 de setembro e 24 de outubro a 17 de novembro de 2009 , favoreceram a redução da condutividade elétrica dos grãos, mas a aeração de milho úmido (17 de agosto a 10 de setembro de 2009) em condições de umidade de equilíbrio causou elevação dos valores de condutividade elétrica, em todas as alturas do silo.

\section{LITERATURA CITADA}

Amaral, K. A. S.; Nascimento, G. B.; Sekiyama, B. L.; Janeiro, V.; Machinski JR, M. Aflatoxinas em produtos à base de milho comercializados no Brasil e riscos para a saúde humana. Ciência e Tecnologia de Alimentos, v.26, p,336-342, 2006.

Antonello, L. M.; Muniz, M. B.; Brand, S. C.; Vidal, M. D.; Garcia, D.; Ribeiro, L.; Santos, V. Qualidade de sementes de milho armazenadas em diferentes embalagens. Ciência Rural, v.39, p.2191-2194, 2009.

AOSA - Association of Official Seed Analysts. Seed vigor testing handbook. East Lansing: AOSA, 1983. 88p. Contribution, 32

Bhatnagar, D.; Lillehoj, E. B.; Arora, D. K. Mycotoxins in ecological systems. Handbook of Applied Mycology. 5ed. New York: Marcel Dekker, 1992.443p.

Costa, P. S. C.; Carvalho, M. L. M. Teste de condutividade elétrica individual na avaliação da qualidade fisiológica de sementes de café (Coffea arabica L.). Ciência e Agrotecnologia, v.30, p.92-96, 2006.

Fessel, S. A.; Sader, R.; Paula, R. C.; Galli, J. A. Avaliação da qualidade física, fisiológica e sanitária de sementes de milho durante o beneficiamento. Revista Brasileira de Sementes, v.25, p.70-76, 2003.
Kawashima, L. M.; Soares, L. M. V. Incidência de fumonisina B1, aflatoxinas B1, B2, G1 e G2, ocratoxina A e zearalenona em produtos de milho. Ciência e Tecnologia de Alimentos, v.26, p.516-521, 2006.

Lin, S. S. Efeito do período de armazenamento na lixiviação eletrolítica dos solutos celulares e qualidade fisiológica da semente de milho (Zea mays L.) e feijão (Phaseolus vulgaris L.). Revista Brasileira de Sementes, v.10, p.59-67, 1988.

Machado, J. C. Patologia de sementes: fundamentos e aplicações. Brasília: Ministério da Educação; Lavras: ESAL/ FAEPE, 1988. 107p.

Márcia, B. A.; Lazzari, F. A. Monitoramento de fungos em milho em grão, grits e fubá. Ciência e Tecnologia de Alimentos, v.18, p.363-367, 1998.

Pinto, N. F. J. A.; Vargas, E. A.; Preis, R. A. Qualidade sanitária e produção de fumonisina B1 em grãos de milho na fase de pré-colheita. Summa Phytopathologica, v.33, p.304-306, 2007.

Ribeiro, S. A. L.; Cavalcanti, M. A. Q.; Fernandes, M. J. S.; Lima, D. M. M. Fungos filamentosos isolados de produtos derivados do milho comercializados em Recife, Pernambuco. Revista Brasileira de Botânica, v.26, p.223-229, 2003.

Rosa, S. D. V. F.; von Pinho, E. V. R.; Vieira, M. G. G. C.; Veiga, R. D. Eficácia do teste de condutividade elétrica para uso em estudos de danos de secagem em sementes de milho. Revista Brasileira de Sementes, v.22, p.54-63, 2000.

Silva, N.; Junqueira, V. C. A.; Silveira, N. F. A.; Taniwaki, M. H.; Santos, R. F. S.; Gomes, R. A. R.; Okazaki, M. M. Manual de métodos de análise microbiológica de alimentos. 3.ed. São Paulo: Varela, 2007. 552p.

Tanaka, M. A. S.; Maeda, J. A.; Plazas, I. H. A. Z. Microflora fúngica de sementes de milho em ambientes de armazenamento. Scientia Agricola, v.58, p.501-508, 2001.

Torres, S. B.; Medeiros, M. A.; Tosta, M. S.; Costa, G. M. M. Teste de condutividade elétrica em sementes de gergelim. Revista Brasileira de Sementes, v.31, p.70-77, 2009. 